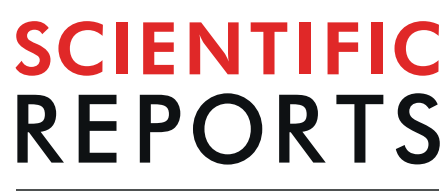

natureresearch

\title{
Snowfall Variability Dictates Glacier Mass Balance Variability in Himalaya-Karakoram
}

\author{
Pankaj Kumar $\mathbb{D}^{1 *}$, Md. Saquib Saharwardi ${ }^{1}$, Argha Banerjee ${ }^{2 *}$, Mohd. Farooq Azam ${ }^{3}$, \\ Aditya Kumar Dubey $\mathbb{1}^{1}$ \& Raghu Murtugudde $\mathbb{B}^{4}$
}

Glaciers in the Himalaya-Karakoram (HK) are critical for ensuring water-security of a large fraction of world's population that is vulnerable to climate impacts. However, the sensitivity of HK glaciers to changes in meteorological forcing remains largely unknown. We analyzed modelled interannual variability of mass balance $(\mathrm{MB})$ that is validated against available observations, to quantify the sensitivity of MB to meteorological factors over the HK. Within the model, snowfall variability $(0.06 \mathrm{~m} /$ yr) explains $\sim 60 \%$ of the MB variability $(0.28 \mathrm{~m} / \mathrm{yr})$, implying a sensitivity of MB on snowfall to the tune of several hundreds of percent. This stunningly high sensitivity of MB to snowfall offers crucial insights into the mechanism of the recent divergent glacier response over the HK. Our findings underscore the need for sustained measurements and model representations of the spatiotemporal variability of snowfall, one of the least-studied factors over the glacierized $\mathrm{HK}$, for capturing the large-scale and yet region-specific glacier changes taking place over the HK.

The Himalaya-Karakoram (HK), covering a glacierized area of $\sim 41,000 \mathrm{~km}^{2}$ is one of the largest mountain ranges on Earth ${ }^{1}$. HK is surrounded by densely populated countries of south Asia and more than 800 million people depend strongly on water originating in its river systems (Indus, Ganges and Brahmaputra) for drinking, irrigation, hydropower, and industrial purposes ${ }^{2,3}$. Given the intrinsic variability of regional precipitation fed by Western Disturbances (WDs) and Indian Summer Monsoon (ISM), HK glaciers buffer a significant fraction of the population against droughts ${ }^{3}$. Climate change is threatening the future of glaciers in the $\mathrm{HK}^{4}$, putting this dynamic water reserve under severe stress and causing serious hydrological changes ${ }^{3,5,6}$. This is likely to expose a significant fraction of regional population to serious climate impacts ${ }^{3,7,8}$. Understanding the details of the climatic forcing that is driving the glacier changes over the $\mathrm{HK}$, therefore becomes an imperative for future adaptation and mitigation strategies.

The glaciers over Karakoram are mostly fed by snowfall occurring during winter months (November to April) derived from WDs while glaciers in the Himalaya receive snowfall from both WDs and ISM ${ }^{9}$. Region-wide remote-sensing glacier mass balance (MB) estimates have revealed that HK glaciers have mostly been experiencing a mass loss in recent decades ${ }^{10,11}$. Available field data from a handful of Himalayan glaciers also confirm this fact ${ }^{12,13}$. However, the pattern of the mass loss is quite heterogeneous; glaciers in the Himalaya are losing mass at rates that vary locally ${ }^{11,12}$ while Karakoram glaciers have been in a near mass-balanced state over the past few decades $^{10,14,15}$. The anomalous behavior, initially termed as "Karakoram Anomaly"16,17, is now found to be centered in Kun Lun Shan ${ }^{10}$. The heterogeneous mass balance behavior over HK points to local idiosyncrasies of net climate forcing and glacier response that await a clear explanation.

Due to the harsh field conditions, only a few studies have been attempted to understand the meteorological forcing of glacier MB in the HK using in-situ data ${ }^{18,19}$. Relevant meteorological field-data from the glacierized high mountains of the region are quite limited ${ }^{20,21}$. A few model studies have investigated the regional glacier MB patterns utilizing various interpolated/reanalyzed meteorological data products ${ }^{21-24}$. A recent study ${ }^{25}$ elucidated the importance of local MB sensitivity to temperature in determining glacier response. Another study using station data over the Karakoram and Tibetan Plateau suggested that cooling summertime surface air temperatures induce less glacier melting over the Karakoram. This cooling is further linked with the "Karakoram Vortex" under

${ }^{1}$ Earth and Environmental Sciences, Indian Institute of Science Education and Research Bhopal, Bhopal, 462066, India. ${ }^{2}$ Earth Climate Sciences, Indian Institute of Science Education and Research Pune, Pune, 411008, India. ${ }^{3}$ Discipline of Civil Engineering, Indian Institute of Technology Indore, Indore, 453552, India. ${ }^{4}$ University of Maryland, College Park, USA. *email: kumarp@iiserb.ac.in; argha@iiserpune.ac.in 

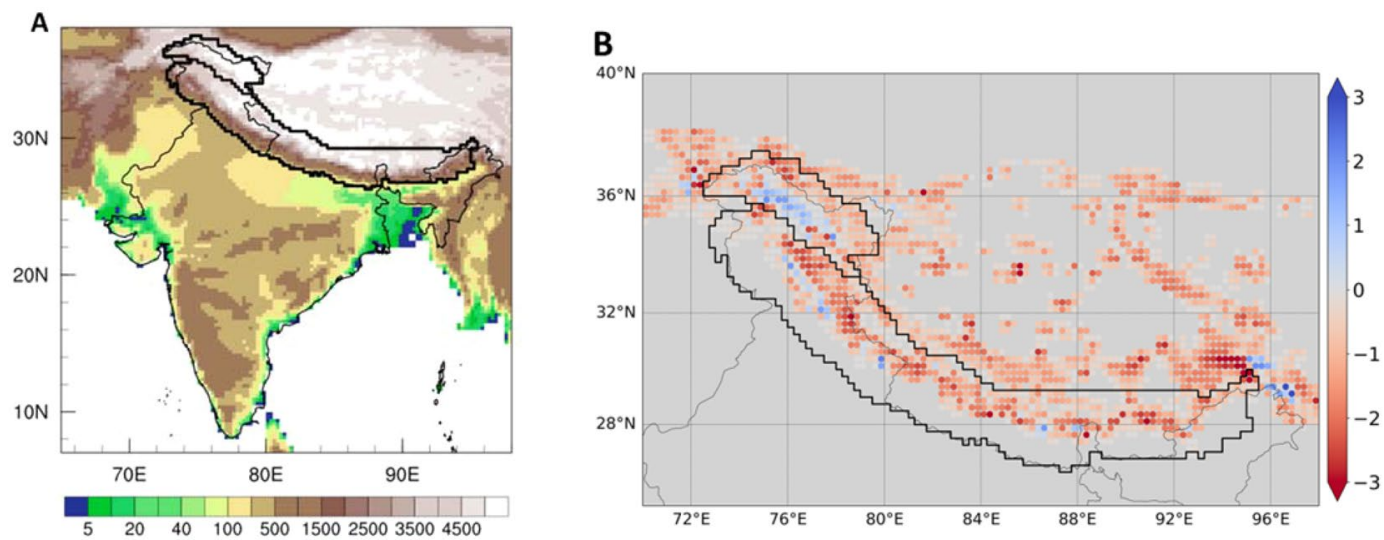

Figure 1. Spatial pattern of mass balance. (A) The model domain with topography (meter). (B) The modelled MB (m.w.e./yr) pattern over the simulated domain, for the period 1989-2016.

climate warming scenarios ${ }^{26,27}$. The vortex modulates the air temperature over the western Tibetan Plateau mainly through adiabatic sinking/rising processes ${ }^{28}$. However, the role of other meteorological parameters in driving the observed spatiotemporal pattern of glacier mass loss in the HK remains largely unexplored. A clear answer to the questions about drivers of $\mathrm{HK}$ glaciers in a warming world is needed to guide future developments related to measurement and modelling strategies to advance process and predictive understanding, and to deliver reliable projections for this dynamic storage of water.

Glacier MB variability is a net result of climatic forcing, which consists of surface MB and a relatively slow response of ice flow ${ }^{29}$. While the long-term $\mathrm{MB}$ trends reflect the combined effects of these, the short-term interannual fluctuations of $\mathrm{MB}$ are mostly due to the meteorological forcing. Therefore, the correlations between annual time series of glacier $\mathrm{MB}$ and the meteorological variables encode the sensitivity of the former to changes in the latter. In fact, the interannual variability of glacier $\mathrm{MB}$ is rather large relative to the recent long-term net $\mathrm{MB}$ especially in the Himalaya ${ }^{12}$. It is also expected that some of the drivers themselves vary coherently due to mutual feedbacks.

Glacier surface MB is determined by a balance between accumulation and ablation, with the ablation being controlled by the net incoming energy flux at the surface. The major contributor to accumulation is snowfall (SF), while the surface energy balance is mostly determined by the balance of short-wave (SW) and long-wave (LW) radiation, sensible heat flux (SHF) exchanged with the atmosphere, and latent heat flux (LHF) due to moisture exchange with the atmosphere via sublimation and condensation,

$$
M B=S F-(S W+L W+S H F+L H F) / \rho L+\varepsilon .
$$

Where $\rho$ density of ice, $\mathrm{L}$ is is latent heat of melting, and $\varepsilon$ denotes relatively minor contributions to this balance; e.g., that due to refreezing of melt-water, conductive heat flux, geothermal and frictional heating, etc ${ }^{30}$.

The primary objective of the present study is to identify the major meteorological drivers of MB fluctuation over the $\mathrm{HK}$ region. We first discuss the performance of the model in capturing the variability of $\mathrm{MB}$ from regional to individual glacier scale. Then we analyze the drivers of the modelled interannual MB variability within the model assumptions. The implications of the results are discussed in the context of the 'Karakoram anomaly'.

\section{Results and Discussion}

Modelled mass balances. A previous study ${ }^{24}$ established that REgional MOdel (REMO) coupled with a dynamic glacier scheme $\left(\mathrm{REMO}_{\text {glacier }}\right)$ is capable of reproducing the general pattern of decadal-scale glacier mass changes in the High Mountain Asia, including the Karakoram Anomaly ${ }^{16,17}$. In the present study, annual MBs over the HK region during 1989-2016 are simulated using $\mathrm{REMO}_{\text {glacier }}$ for the glacierized fraction of each grid cell (Fig. 1B). $\mathrm{REMO}_{\text {glacier }}$ simulates a negative $\mathrm{MB}$ over most parts of the region except the Karakoram. These positive MBs over the Karakoram and Kunlun mountain range have been addressed by several studies ${ }^{24,31}$. In this study, the modelled mean glacier MBs were estimated to be -0.74 m.w.e./yr for the Himalaya and 0.06 m.w.e./yr for the Karakoram between 1989 and 2016 (Table S2). The estimated value for the Himalaya suggests a negative bias in the model result. However, the model reproduces the general pattern of glacier mass loss in the HK (Fig. 1). There are some isolated gridboxes with positive MB values (Fig. 1B) that are not consistent with observed glacier MB. These are likely to be model artifacts related to steep topographic gradients between neighboring gridboxes ${ }^{24}$.

Region-wide validation of modelled mass balances. We compared the modelled MBs with the latest remotely sensed geodetic MB estimates across the HK for the period 2000-2016 ${ }^{11}$. There is a reasonable match between these two datasets at regional to sub-regional level (Fig. 2, Table 1), though model estimates are systematically more negative. There is a large variability in both the modelled and geodetic estimates over gridboxes with a small glacier fraction added to the spatial noise. Also, as discussed in ref. ${ }^{24}$, the lack of a description of the large-scale flow within model gridboxes may exaggerate the snowfall variability from one gridbox to another, leading to an inflated spatial variability of modelled MB. This limitation is discussed in detail in a previous study 


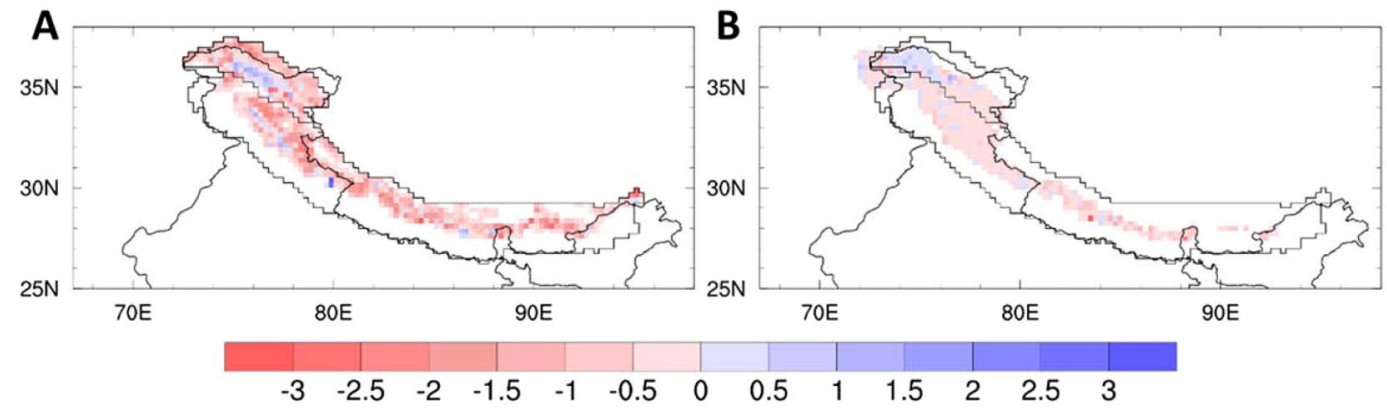

Figure 2. Comparison of $\mathrm{REMO}_{\text {glacier }}$ with geodetic data (A) $\mathrm{REMO}_{\text {glacier }}$ simulated mean $\mathrm{MB}$ (m.w.e./yr) comparison with (B) Geodetic MB calculated (for details ref. ${ }^{11}$ ) (m.w.e./yr) for the period 2000-2016. For model, all the glacier fraction gridboxes covering the data is represented.

\begin{tabular}{|l|l|l|l|l|}
\hline Regions & Measurement & Period (yr) & $\begin{array}{l}\text { Modelled (m.w.e./ } \\
\mathbf{y r})\end{array}$ & $\begin{array}{l}\text { Observed } \\
\text { (m.w.e./yr) }\end{array}$ \\
\hline Himalaya & Geodetic & $2000-2016$ & $-0.72 \pm 0.05$ & $-0.39 \pm 0.02$ \\
\hline Karakoram & Geodetic & $2000-2016$ & $-0.09 \pm 0.09$ & $-0.05 \pm 0.03$ \\
\hline HK & Geodetic & $2000-2016$ & $-0.39 \pm 0.06$ & $-0.28 \pm 0.03$ \\
\hline CSG & Field & $2003-2014$ & $-0.12 \pm 0.10$ & $-0.56 \pm 0.18$ \\
\hline Mera & Field & $2008-2015$ & $-0.03 \pm 0.14$ & $-0.02 \pm 0.15$ \\
\hline Pokalde & Field & $2010-2015$ & $-0.006 \pm 0.15$ & $-0.69 \pm 0.20$ \\
\hline Himalaya (pentad*) & Field & $1990-2014$ & $-0.76 \pm 0.05$ & $-0.72 \pm 0.09$ \\
\hline
\end{tabular}

Table 1. Validation of modelled mass balances with available mass balances (m.w.e./yr) for Himalaya, Karakoram and Chhota Shigri (CSG), Mera and Pokalde Glaciers over different time periods. *Pentad observation is the mean of 24 glaciers where some glaciological MB data is available.

(for details see ref. ${ }^{24}$ ). Despite the model limitations, the general consistency model data with observation as described above indicates the overall reliability of the modelled regional MB.

We also validated the simulated MBs over the Himalaya with pentadal ( 5 year) averages of all the available glaciological field measurements of MB from 24 glaciers in the Himalayan region ${ }^{12}$ (Fig. 3A). Here, the observed pentadal MBs are the averages of all the available field measurements of glacier MB for the corresponding pentad from the entire Himalaya during 1990 to 2014. The model captures the observed pentadal average MBs from the Himalaya reasonably well (Table 1), though the standard deviation of modelled pentadal MB is relatively smaller (Fig. 3A). We note that a possible negative bias in the observed MB due to avalanches and other effects was pointed out in $\mathrm{MB}$ series of some of these glaciers ${ }^{12,32}$ making gridbox scale comparison difficult. Regrettably, no annual glaciological MBs from any of the Karakoram glaciers are available ${ }^{12}$.

Glacier-wide validation of modelled mass balances. Chhota Shigri Glacier has the longest observed MB time series in the whole Himalaya since $2003^{18}$. For glacier-wide model validation, we simulated the annual MBs on Chhota Shigri Glacier and compared them with observed MBs for the period 2003-2014 (Fig. 3B). The model is reasonably good at capturing the individual glacier mass balances (Table 1) and interannual variability (Fig. 3B), corresponding correlation (0.53) is significant at $~ 95 \%$ confidence level. Additionally, model results were compared with $\mathrm{MB}$ data ${ }^{19}$ from two more glaciers in the Himalaya, namely, Mera (Fig. 3C) and Pokalde glaciers (Fig. 3D) for relatively shorter periods of 8 and 6 years, respectively. Interestingly, the interannual variability of MB was also well captured for Mera and Pokalde glaciers (Fig. 3C,D) with significant correlations. However, it must be noted that given the coarse resolution, and a simplified description of glacier dynamics and geometry, it is not expected that the model would be able to reproduce glacier-scale MB accurately for any given glacier over a particular balance year. For example, the positive trend of the observed annual MBs for Chhota Shigri is not captured well in the corresponding modelled time series, and there is a clear positive bias in the modelled MBs for Chhota Shigri and Mera glaciers (Table 1).

Overall, the model may not reproduce local-scale glacier-specific MBs accurately due to inherent model limitations and has a negative bias in the case of regional-scale MBs. However, it does a reasonable job of reproducing the general spatial pattern of mean multi-decadal MB (Figs. 1,2), the typical magnitudes of regional MBs (Table S1), and pentadal to annual-scale variability (Fig. 3).

Apart from glacier-wide MB, we have also compared the annual snowfall in four western Himalayan stations for which we could access the data. The model seems to be able to capture the observed interannual variability and magnitude of snowfall at these stations reasonably well (see Supplementary Fig. S1). A reasonable model performance in reproducing observed precipitation and temperature has already been established in ref. ${ }^{24}$. 

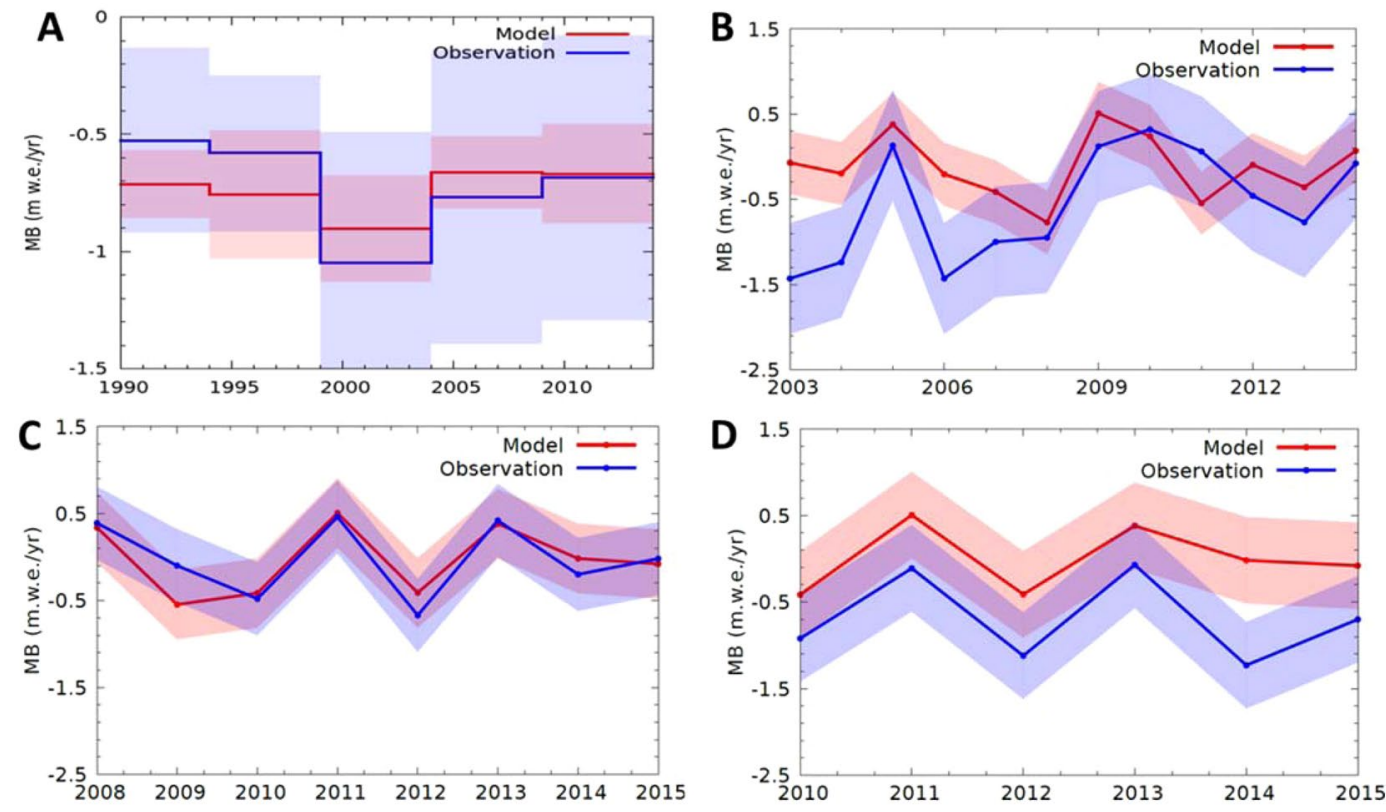

Figure 3. Mass-balance variability in the Himalaya. (A) A comparison of pentadal averages of modelled annual MBs (red line) with that of pentadal averages from all the available field observations of MBs (blue line) from 24 glaciers over 1990-2014 period ${ }^{12}$. (B) A comparison of modelled annual MB (red line) with that of available field annual MBs (blue line) on Chhota Shigri Glacier over 2003-2014 ${ }^{18}$, (C) Mera Glacier for period 2008$2015^{18}$ (D) Pokalde Glacier for 2010-2015 ${ }^{18}$. Corresponding $1-\sigma$ bands are also shown.
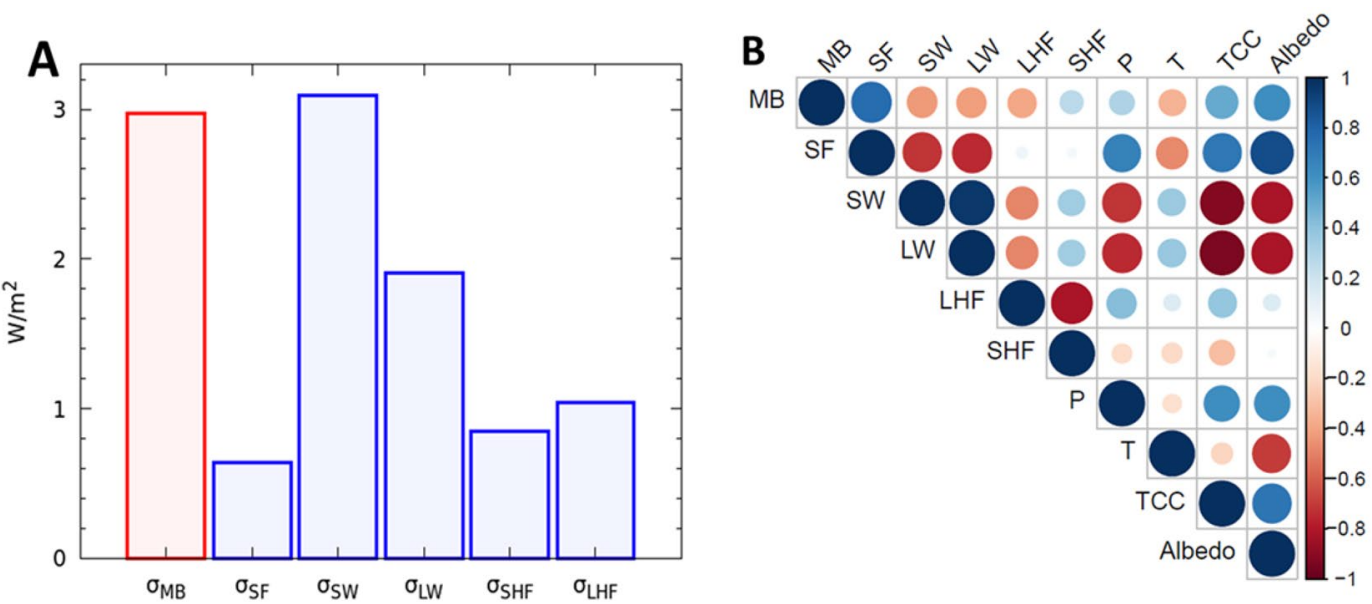

Figure 4. The variability of $\mathrm{MB}$ and its drivers. (A) The variance $(\sigma)$ of annual $\mathrm{MB}$ (red bar), and that of the dominant mass/energy-balance terms (blue bars) that contribute to it, viz., annual snowfall (SF), net shortwave energy (SW), net long-wave energy (LW), sensible heat flux (SHF), latent heat flux (LHF). All mass terms are expressed in equivalent energy units $\left(\mathrm{W} / \mathrm{m}^{2}\right)$ for ease of comparison. (B) A graphical representation of correlations among the interannual variability of glacier $\mathrm{MB}$ in the $\mathrm{HK}$ and its meteorological drivers during 1990-2016. The dominant control of SF variability over that of MB fluctuation is evident.

Fluctuations of modelled mass balance and its drivers. Our analysis of the 28-year-long time series of modelled MBs and the associated meteorological parameters over the HK revealed that SW has the largest interannual variability, followed by MB, LW, LHF and SHF, respectively (Fig. 4A). Notably, among the parameters considered, SF has the smallest variability in absolute terms. If these fluctuations were to be uncorrelated, the expected variance of annual $\mathrm{MB}$ of the HK glaciers would be obtained by combining the variance of the drivers in quadrature, which turns out to be about $4 \mathrm{~W} / \mathrm{m}^{2}$. However, the observed interannual MB variance is equivalent to only about $3 \mathrm{~W} / \mathrm{m}^{2}$ (Fig. $4 \mathrm{~A}$ ). This suggests that there are strong correlations among the drivers. Thus, the net effect of a specific driver on MB, despite having a large variance, may be small due to the cancelling effects of other drivers. In contrast, a positive correlation among drivers could magnify the effect of the ones with a relatively weak variability. To untangle such cancelling/enhancing effects on $\mathrm{MB}$, we analyzed correlations between all the 


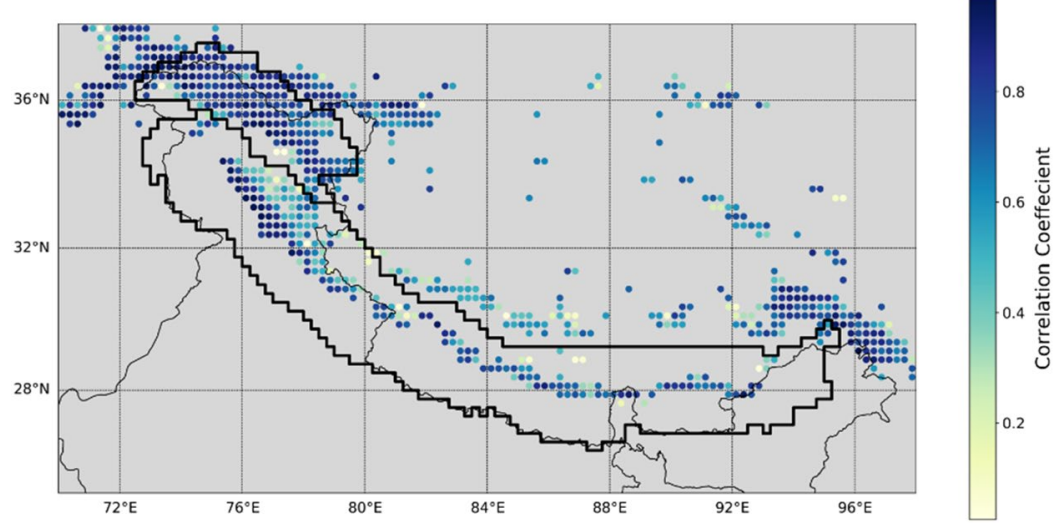

Figure 5. SF correlation with MB (1990-2016). MB and SF over the HK have a strong correspondence, revealing the control of the variability of $\mathrm{SF}$ on that of $\mathrm{MB}$.

possible pairs of fluxes listed above and MB. In addition, annual precipitation (P), temperature (T), total cloud cover (TCC), and albedo were considered. The results are shown in Fig. 4B (also see Supplementary Fig. S2, see Supplementary Fig. S3) and discussed in the next section.

Snowfall variability as the major driver for mass balances. The correlation matrix (Fig. 4B and Supplementary Fig. S3) reveals that SF variability has the strongest correlation with the MB response, with a correlation coefficient (CC) of $0.76(\mathrm{p}<0.001)$ within our model assumptions. It is quite surprising that the interannual $\mathrm{MB}$ variability of $0.28 \mathrm{~m}$.w.e./yr in the $\mathrm{HK}$ is so tightly controlled by the interannual variability of SF that has a relatively small magnitude of only $0.06 \mathrm{~m}$.w.e./yr. This implies a strong MB sensitivity of $\sim 470 \%$ to changes in SF in the HK. The reason behind this is that SF not only contributes directly to the accumulation, but it also has a strong effect on net budget of SW $(\mathrm{CC}=-0.72, \mathrm{p}<0.001)$ through its control on albedo $(\mathrm{CC}=0.88, \mathrm{p}<0.001)$ and association with TCC $(\mathrm{CC}=0.71, \mathrm{p}<0.001)$. Both albedo and TCC, with their respective variability of $5 \%$ and $8 \%$ within the model, exert a strong influence on the radiation budget in the HK. Thus, cooperation among the above factors amplifies the net effect of SF variability on $\mathrm{MB}$, resulting in a very large sensitivity of MB to changes in SF.

The correlation analysis also reveals that the role of SF is stronger in the Karakoram than in the Himalaya (see Supplementary Fig. S4). The surprisingly dominant role of SF in controlling MB is also verified with a principal-component analysis (PCA) of the correlation matrix (see Supplementary Fig. S5). This critical role of the SF variability as a MB driver is, in fact, evident from a simple and yet striking plot of both the time series (see Supplementary Fig. S4) and spatial correlation of SF and MB (Fig. 5). The CC is high over the Karakoram and parts of Eastern Himalaya where glacier-fraction is relatively high. However, its value over the Western Himalaya is lower than other regions because glacier fraction is quite low ( $<10 \%$; see Supplementary Fig. S6). Hence small changes in magnitude may show a relatively large variability. Regions with higher (lower) SF have significant (insignificant) correlations between SF and MB, which is seen in both the model and ERA-Interim reanalysis (ERAI) data (see Supplementary Fig. S7). The spatial correlation between these two datasets also depicts the same pattern (see Supplementary Fig. S7). This analysis provides further evidence that indeed SF has a strong relationship with $\mathrm{MB}$ over the whole region of study, and that this result is not a model artifact.

We note that instead of mean annual temperature, using summer (JJA) temperatures improves the correlation with MB (see Supplementary Fig. S8). However, this does not necessarily imply a stronger control of SHF on MB, as the net radiation budget is known to play a dominant role in controlling glacier melt ${ }^{33}$. The stronger correlation with summer temperature is expected as temperature is a good indicator of net local energy budget ${ }^{34}$.

Relative insensitivity of MB in the karakoram to temperature change. Our model results suggest similar warming trends in both the Himalaya and the Karakoram, with a rate of temperature change of about $0.3^{\circ} \mathrm{C}$ per decade $(\mathrm{p}<0.1)$ (see Supplementary Fig. S9). While no precipitation trends are seen in either of the regions for the study period as per the model results, any local warming can influence the partitioning of total precipitation into snow and rain, leading to a reduction in SF. The same insignificant changes in precipitation have been reported earlier over the Karakoram region ${ }^{35,36}$. Indeed, the above warming is accompanied by a statistically significant $0.08 \mathrm{~mm}$ /day per decade reduction of SF in the Himalaya $(\mathrm{p}<0.1)$ (see Supplementary Fig. S9). However, SF has not changed significantly in the Karakoram during this period (see Supplementary Fig. S9) suggesting a lower sensitivity of SF over the Karakoram to warming. This is consistent with the argument ${ }^{22}$ that a dominant wintertime snowfall in the cold Karakoram has been insensitive to local warming thus far. We note that, alternatively, the variability of a large-scale circulation system, the so-called "Karakoram Vortex", has been argued to have led to a recent summertime cooling over the Karakoram ${ }^{26,27}$. This alternative explanation of the Karakoram anomaly does not rely on the above-mentioned insensitivity of glacier mass balance to annual temperature variability in the Karakoram. However, these results do not rule out that a dominant wintertime SF in Karakoram is less prone to conversion into rain as argued by ref. ${ }^{22}$ and supported by our model results. 
In contrast to the situation in the Karakoram, a monsoon-derived summer snowfall in the Himalaya is negatively affected by local warming, causing more rainfall at the expense of solid precipitation. Thus, strongly monsoon-fed Himalayan glaciers have a higher sensitivity of MB to temperature change. This, together with the strong control of SF on MB described above, lead to a strongly negative mass budget for the Himalayan glaciers within the model.

The above contrast in the response of SF to local temperature changes is likely to be one of the root causes for the divergent behavior of glaciers in the Himalaya and Karakoram in a warming climate. The same inference can be deduced from the fact that there is no significant correlation between local interannual temperature fluctuation and SF in the Karakoram, but in the Himalaya the two are locally anti-correlated $(C C=-0.65, \mathrm{p}<0.001)$ (see Supplementary Fig. S10) within our model assumptions.

\section{Summary and Conclusion}

The annual MBs of the HK region are simulated using $\mathrm{REMO}_{\text {glacier }}$ over the 1989-2016 period. The spatial patterns of simulated MB show an overall negative mass balance but also reveal regions with positive mass balance anomalies especially over the Karakoram. This positive MB is also highlighted in previous studies. However, there is an overall negative bias in our modelled $\mathrm{MB}$ that may likely be related to biases in atmospheric forcing during the simulations or due to the effects of unresolved topography and relief, and unaccounted for local circulation effects. For the whole HK region, it has been found that MB simulated by model is able to capture observational variability reasonably well. An analysis of the model data reveals that the annual glacier MB variability in the HK over the last two and half decades is essentially driven by the variability of mean annual snowfall. We also show that, within the model, a relative insensitivity of snowfall to the local temperature changes are responsible for the Karakoram anomaly, while the negative impact of climate warming on monsoon-derived summer snowfall in the Himalaya forces a net negative MB in the region. It is thus apparent that understanding the recent and future climate forcing and the corresponding response of the glaciers at the third pole would require a strong handle on snowfall variability and its trend. For example, can the winter warming cross the threshold beyond which winter snowfall would be affected significantly even in the Karakoram? Unfortunately, snowfall is one of the biggest unknowns in the region, with very scant or no long-term field data ${ }^{20,37}$. While snow-cover extent and albedo are accessible through remote-sensing measurements, the snow-water-equivalent - which is crucial for any glaciological or hydrological mass-budget considerations - is difficult to constrain from satellite data ${ }^{38,39}$. There has been a spate of scientific activities over the past decade or so, as far as remote-sensing and field-based observations, and modelling of glacier dynamics in the HK are concerned. This has led to a significant process understanding of the response of $\mathrm{HK}$ glaciers and their role in the regional water cycle. Our results indicate that snowfall needs to be targeted more specifically, if the efforts to piece together a complete picture of the water-cycle in the glacierized $\mathrm{HK}$ are to succeed. The broader impact of our results can hardly be overemphasized in terms of the need to understand the glacier-specific extraction of seemingly weak climate links to understand the net impact of global warming on glacier mass budgets.

\section{Data and Methods}

Regional model REMO. The REgional MOdel (REMO) is a regional climate model ${ }^{40,41}$ which derives its dynamic core from the Europa Model of the German weather service ${ }^{42}$. It uses a rotated grid with the equator in the middle of the model domain to avoid disproportionate grid sizes towards the poles. The horizontal coordinates are discretized on the Arakawa C-grid, and there are 27 vertical hybrid levels ${ }^{43}$. Time discretization follows the leapfrog time stepping with semi-implicit correction and Asselin filter smoothing. The prognostic variables of REMO are surface pressure, temperature, horizontal wind components, water vapour and cloud water content. The model uses a fourth order linear horizontal diffusion of momentum, temperature and water content ${ }^{44}$. A sponge zone of 8 gridboxes exists at the boundary of the model domain ${ }^{45}$ where the lateral boundary conditions are applied for the aforementioned prognostic variables.

The physical parameterizations for REMO are adopted from the global climate models ECHAM4 and $5^{46,47}$. Soil heat transfer is based on a 5-layer model to a depth of $10 \mathrm{~m}$ where heat flux is set to zero at the bottom. Water budget equations are solved for the three reservoirs: soil moisture, vegetation (interception reservoir) and snow while the runoff scheme is based on ${ }^{48}$ which considers sub-grid scale variations of field capacity over the inhomogeneous terrain. A radiative upper boundary condition following ${ }^{49,50}$ is applied. Radiation (SW and LW) is parameterized ${ }^{51}$ with modifications for ECHAM4 provided $^{47}$.

Glacier scheme. A dynamic glacier scheme (DGS) is developed and implemented in REMO. DGS has a unique ability to simulate the $\mathrm{MB}$ and dynamically adjusted glacier-surface fraction of each gridbox depending on the accumulation and ablation conditions ${ }^{52}$. To augment DGS online with REMO, in addition to the standard REMO gridbox fractions mentioned above, a fourth fraction for glaciers has been introduced ${ }^{52}$. REMO with this fourth glacier fraction is hereafter referred to as $\mathrm{REMO}_{\text {glacier }}$ A glacier fraction in a $\mathrm{REMO}_{\text {glacier }}$ gridbox includes the total area covered by glaciers in that gridbox. Glaciers are allowed to grow and shrink according to their MB, but they are restricted to the land fraction of a single model gridbox and are not allowed to expand over water. Individual glaciers in a single gridbox are represented by a two-layered cuboid of surface area A and thickness $h$, corresponding to a volume V. Since glacier thickness has been shown to depend on glacier area ${ }^{53,54}$, glacier area is used to calculate volume from a power law relation, $\mathrm{V}=\mathrm{cA} \gamma$ where $\mathrm{c}$ and $\gamma$ are empirical constants ${ }^{55}$.

The surface energy balance is calculated at each time step for the glacierized fraction according to the following equation:

$$
\mathrm{dQice} / \text { snow }=\mathrm{SW}+\mathrm{LW}+\mathrm{SHF}+\mathrm{LHF}+\mathrm{G}+\mathrm{M}
$$


where $\mathrm{G}$ is ground heat flux, $\mathrm{M}$ is amount of energy consumed during melt of snow and ice, and dQice/snow is the energy change of heat content in the upper snow or ice layer.

Experimental setup and analysis. $\mathrm{REMO}_{\text {glacier }}$ is integrated over South-Asia (Fig. 1A) for the period 1989-2016 at a horizontal resolution of $0.22^{\circ} \times 0.22^{\circ}(\sim 25 \mathrm{~km})$ with 27 vertical levels and forced by the ERA-Interim reanalysis (ERAI) dataset ${ }^{56}$ as the lateral boundary conditions. The update of lateral boundaries has a temporal resolution of 6 hours and is interpolated into a two-minute time step. The glacier volume data ${ }^{57,58}$ is

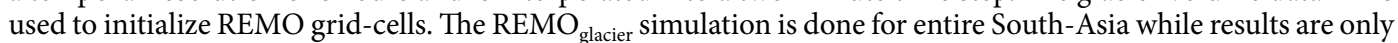
shown for Karakoram $(\mathrm{K})$ and Himalayan $(\mathrm{H})$ regions (as defined in ref. ${ }^{1}$ ).

Statistical analysis. The analyses focus on simulated annual (1 October to 30 September of next year) mean statistics of various model parameters and are compared against the available observations. Different statistical methods have been used to determine correlations, trends, and significance analysis. The standard Pearson-correlation method has been used to determine the relationship between variables, while student $\mathrm{t}$-test is used to assess the significance of the correlation. Mann-Kendall test is a well defined method to determine the non-parametric monotonic trend in the dataset with the significance level ${ }^{59-61}$. We used this test to determine the trend of $\mathrm{MB}$ as well as other parameters to check whether statistical significance changes with time. Principle component analysis (PCA) is the multivariate analysis method to determine the degree of relationship among variables for redundancy reduction ${ }^{62,63}$. We used PCA to describe the variable that is the best estimate of MB variability over the study region.

Observational datasets employed. The model-simulated results are compared with different observational data sets. The ERAI ${ }^{56}$ and $\mathrm{ERA} 5^{64}$ reanalysis products, along with Indian Meteorological Department (IMD) station data from four western Himalayan stations are used for comparison of SF with modelled MB. The geodetic pentadal dataset of $\mathrm{MB}^{12}$ over the whole Himalaya is used to validate the model for the period 1990-2014. The glaciological mass balance for the period 2003-2014 over Chhota Shigri glacier, for the period 2010-2015 for Pokalde glacier, and 2008-2015 for Mera glacier ${ }^{18}$ are further used to assess the performance of the model to capture individual glaciers' MB values. To cover the whole HK region, ASTER geodetic MB data at $0.25^{\circ} \times 0.25^{\circ}$ is used ${ }^{11}$ for the period $2000-2016$.

\section{Data availability}

Datasets are given in the supplementary Information. The additional dataset that support the findings of this study are available from the corresponding author on reasonable request.

Received: 24 May 2019; Accepted: 7 November 2019;

Published online: 03 December 2019

\section{References}

1. Bolch, T. et al. The state and fate of Himalayan glaciers. Science 336(6079), 310-314 (2012).

2. Immerzeel, W. W., Pellicciotti, F. \& Bierkens, M. F. P. Rising river flows throughout the twenty-first century in two Himalayan glacierized watersheds. Nat Geosci 6, 742-745 (2013).

3. Pritchard, H. D. Asia's glaciers are a regionally important buffer against drought. Nature 545(7653), 169-174 (2017).

4. Kraaijenbrink, P. D. A., Bierkens, M. F. P., Lutz, A. F. \& Immerzeel, W. W. Impact of a global temperature rise of 1.5 degrees Celsius on Asia's glaciers. Nature 549(7671), 257 (2017).

5. Barnett, T. P., Adam, J. C. \& Lettenmaier, D. P. Potential impacts of a warming climate on water availability in snow-dominated regions. Nature 438(7066), 303-309 (2005).

6. Huss, M. \& Hock, R. Global-scale hydrological response to future glacier mass loss. Nature Climate Change 8, 135-140 (2018).

7. Kaser, G., Grofihauser, M. \& Marzeion, B. Contribution potential of glaciers to water availability in different climate regimes. PNAS. 107(47), 20223-20227 (2010).

8. Lutz, A. F., Immerzeel, W. W., Shrestha, A. B. \& Bierkens, M. F. P. Consistent increase in High Asia's runoff due to increasing glacier melt and precipitation. Nature Climate Change 4(7), 587 (2014)

9. Bookhagen, B. \& Burbank, D. W. D. W. Toward a complete Himalayan hydrological budget: Spatiotemporal distribution of snowmelt and rainfall and their impact on river discharge. J. Geophys. Res. 115, F03019 (2010).

10. Kaab, A., Treichler, D., Nuth, C. \& Berthier, E. Brief Communication: Contending estimates of 2003-2008 glacier mass balance over the Pamir-Karakoram-Himalaya. The Cryosphere 9(2), 557-564 (2015).

11. Brun, F., Berthier, E., Wagnon, P., Kaab, A. \& Treichler, D. A spatially resolved estimate of High Mountain Asia glacier mass balances from 2000 to 2016. Nature geoscience 10(9), 668-673 (2017).

12. Azam, M. F. et al. Review of the status and mass changes of Himalayan-Karakoram glaciers. Journal of Glaciology 64(243), 1-14 (2018).

13. Scherler, D., Bookhagen, B. \& Strecker, M. R. Spatially variable response of Himalayan glaciers to climate change affected by debris cover. Nature geoscience 4(3), 156 (2011).

14. Zhou, Y., Li, Z. \& Li, J. I. A. Slight glacier mass loss in the Karakoram region during the 1970 s to 2000 revealed by KH-9 images and SRTM DEM. Journal of Glaciology 63(238), 331-342 (2017).

15. Bolch, T., Pieczonka, T., Mukherjee, K. \& Shea, J. Brief communication: Glaciers in the Hunza catchment (Karakoram) have been nearly in balance since the 1970s. The Cryosphere 11(1), 531-539 (2017).

16. Hewitt, K. The Karakoram anomaly? Glacier expansion and the "elevation effect," Karakoram Himalaya. Mt. Res. Dev. 25(4), 332-340 (2005)

17. Gardelle, J., Berthier, E. \& Arnaud, Y. Slight mass gain of Karakoram glaciers in the early twenty-first century. Nat. Geosci. 5, 322-325 (2005).

18. Azam, M. F. et al. Meteorological conditions seasonal and annual mass balances of Chhota Shigri Glacier, western Himalaya, India. Annals of Glaciology 57(71), 328-338 (2016).

19. Sherpa, S. F. et al. Contrasted surface mass balances of debris free glaciers observed between the southern and the inner parts of the Everest region (2007-15). Journal of Glaciology 63(240), 637-651 (2017).

20. Putkonen, J. K. Continuous snow and rain data at 500 to $4400 \mathrm{~m}$ altitude near Annapurna, Nepal, 1999-2001. Arctic, Antarctic, and Alpine Research 36(2), 244-248 (2004). 
21. Shea, J. M., Immerzeel, W. W., Wagnon, P., Vincent, C. \& Bajracharya, S. Modelling glacier change in the Everest region Nepal Himalaya. The Cryosphere $9(3), 1105-1128$ (2015).

22. Kapnick, S. B., Delworth, T. L., Ashfaq, M., Malyshev, S. \& Milly, P. C. Snowfall less sensitive to warming in Karakoram than in Himalayas due to a unique seasonal cycle. Nature Geoscience 7(11), 834 (2014).

23. Maussion, F. et al. Precipitation seasonality and variability over the Tibetan Plateau as resolved by the High Asia Reanalysis. Journal of Climate 27(5), 1910-1927 (2014).

24. Kumar, P. et al. Response of Karakoram-Himalayan glaciers to climate variability and climatic change: A regional climate model assessment. Geophysical Research Letters 42(6), 1818-1825 (2015).

25. Sakai, A. \& Fujita, K. Contrasting glacier responses to recent climate change in high-mountain Asia. Scientific reports 7(1), 13717 (2017).

26. Forsythe, N., Fowler, H. J., Li, X.-F., Blenkinsop, S. \& Pritchard, D. Karakoram temperature and glacial melt driven by regional atmospheric circulation variability. Nature Climate Change 7, 664-670 (2017).

27. Li, X.-F., Fowler, H. J., Forsythe, N., Blenkinsop, S. \& Pritchard, D. The Karakoram/Western Tibetan vortex: seasonal and year-toyear variability. Climate Dynamics 52, 3883-3906 (2018).

28. Li, X-F, Fowler, H. J., Forsythe, N., Blenkinsop, S., \& Pritchard, D. Thermodynamic Controls of the Western Tibetan Vortex on Tibetan Air Temperature. Climate Dynamics (2019).

29. Banerjee, A. Brief communication: Thinning of debris-covered and debris-free glaciers in a warming climate. The Cryosphere 11(1), 133-138 (2017).

30. Oerlemans, J. Glaciers and climate change. AA Balkema Publishers, Rotterdam (2001).

31. Dehecq, A. et al. Twenty-first century glacier slowdown driven by mass loss in High Mountain Asia. Nat. Geosci. 12, $22-27$ (2019).

32. Laha, S. et al. Evaluating the contribution of avalanching to the mass balance of Himalayan glaciers. Ann. Glaciol. 58, 110-118 (2017).

33. Azam, M. F. et al. Processes governing the mass balance of Chhota Shigri Glacier (western Himalaya, India) assessed by point-scale surface energy balance measurements. The Cryosphere 8, 2195-2217 (2014).

34. Ohmura, A. Physical basis for the temperature-based melt-index method. Journal of applied Meteorology 40.4, 753-761 (2001).

35. Archer, D. R. \& Fowler., H. J. Spatial and temporal variations in precipitation in the Upper Indus Basin, global teleconnections and hydrological implications. Hydrology and Earth System Sciences Discussions 8, 47-61 (2004).

36. Forsythe, N., Kilsby, C. G., Fowler, H. J. \& Archer, D. R. Assessment of runoff sensitivity in the Upper Indus Basin to interannual climate variability and potential change using MODIS satellite data products. Mountain Research and Development 32, 16-30 (2012).

37. Menegoz, M., Gallee, H. \& Jacobi, H. W. Precipitation and snow cover in the Himalaya: from reanalysis to regional climate simulations. Hydrology and Earth System Sciences 17(10), 3921-3936 (2013).

38. Takala, M. et al. Estimating northern hemisphere snow water equivalent for climate research through assimilation of space borne radiometer data and ground-based measurements. Remote Sensing of Environment 115(12), 3517-3529 (2011).

39. Smith, T. \& Bookhagen, B. Changes in seasonal snow water equivalent distribution in High Mountain Asia (1987 to 2009). Sci. Adv. 4(1), e1701550 (2018)

40. Jacob, D. A note to the simulation of the annual and interannual variability of the water budget over the Baltic Sea drainage basin. Meteorol. Atmos. Phys. 77(1-4), 61-73 (2001).

41. Jacob, D. Regional Climate Models: Linking Global Climate Change to Local Impacts. The Springer Encyclopedia of Complexity and Systems Science (Springer Berlin New York) 7591-7602 (2009).

42. Majewski, D. The Europa modell of the Deutscher Wetterdienst, In Seminar Proceedings ECMWF (ECMWF, Reading, U. K) 2, 147191 (1991).

43. Simmons, A. J. \& Burridge, D. M. An energy and angular momentum conserving vertical finite difference scheme and hybride vertical coordinate. Mon. Weather Rev. 109, 758-766 (1981).

44. Jacob, D. \& Podzun, R. (1997). Sensitivity studies with the regional climate model REMO. Meteorology and Atmospheric Physics 63(1-2), 119-129 (1981).

45. Davies, H. C. A lateral boundary formulation for multi-level prediction models. Q. J. R. Meteorol. Soc. 102, 405-418 (1976).

46. Roeckner, E. et al. The Atmospheric General Circulation Model ECHAM-4: Model description and simulation of present-dayclimate. MPI für Meteorol. (Hamburg, Germany) 218 (1996).

47. Roeckner, E. et al. The atmospheric general circulation model ECHAM 5. PART I: Model description. MPI für Meteorol. (Hamburg, Germany) 349 (2003).

48. Dümenil, L. \& E. Todini, E. A rainfall-runoff scheme for use in the Hamburg climate model In: Advances in Theoretical Hydrology, A Tribute to James Dooge (Ed. J. P. O'Kane). European Geophysical Society Series on Hydrological Sciences (Elsevier Press Amsterdam), 129-157 (1992).

49. Klemp, J. B. \& D. R. Durran, D. R. An upper boundary condition permitting internal gravity wave radiation in numerical mesoscale models. Mon. Weather Rev. 111, 430-444 (1983).

50. Bougeault, P. A non-reflective upper boundary condition for limited-height hydrostatic models. Mon. Weather Rev. 111, 420-429 (1983).

51. Morcrette, J. J. \& Y. Fouquart, Y. Pressure and temperature dependence of the absorption in longwave radiation parameterizations. Beitr. Phys. Atmos. 59, 455-469 (1986).

52. Kotlarski, S., Jacob, D., Podzun, R. \& Paul, F. Representing glaciers in a regional climate model. Climate dynamics 34(1), 27-46 (2010).

53. Müller, F., Caflish, T. \& Müller, G. Firn und Eis der Schweizer Alpen. Gletscherinventar. Geographisches Institut. vdf-Verlag, (ETH Zürich) 57, 174 (1976).

54. Maisch, M. Die Gletscher Graubündens-Rekonstruktion und Auswertung der Gletscher und deren Veränderungen seit dem Hochstand von $1850 \mathrm{im}$ Gebiet der Östlichen Schweizer Alpen. Teil A: Grundlagen-Analysen-Ergebnisse. PhD thesis, University of Zurich (1992).

55. Bahr, D. B., Meier, M. F. \& Peckham, S. D. The physical basis of glacier volume-area scaling. J. Geophy. Res. 102, 20355-20362 (1997).

56. Dee, D. P. et al. The ERA-Interim reanalysis: configuration and performance of the data assimilation system. Q.J.R. Meteorol. Soc. 137, 553-597 (2011).

57. Frey, H. et al. Estimating the volume of glaciers in the Himalayan-Karakoram region using different methods. The Cryosphere $\mathbf{8}$, 2313-2333 (2014).

58. Huss, M. \& Farinotti, D. Distributed ice thickness and volume of all glaciers around the globe. Journal of Geophysical Research 117, F04010 (2012).

59. Mann, H. B. Non-parametric tests against trend. Econometrica 13, 163-171 (1945).

60. Kendall, M. G. Rank Correlation Methods. (Charles Griffin. London) 4 (1975).

61. Gilbert, R. O. Statistical Methods for Environmental Pollution Monitoring. (Wiley, NY) (1987).

62. Hotelling, H. Analysis of a complex of statistical variables into principal components. J. Educ. Psychol. 25, 417-441 (1933).

63. Jolliffe I. T. Principal Component Analysis. (New York: Springer) (2002).

64. Copernicus Climate Change Service (C3S). ERA5: Fifth generation of ECMWF atmospheric reanalyses of the global climate. Copernicus Climate Change Service Climate Data Store (CDS), date of access (2017). 


\section{Acknowledgements}

We thank Fanny Brun for sharing the geodetic mass-balance data used to prepare supplementary section as well as Holger Frey and Matthias Huss for providing the glacier volume data to initialize REMO grid cells. We also thank to Patrick Wagnon for his comments on the initial manuscript. PK thanks the Director, German Climate Service Center (GERICS) Germany for REMO support. PK acknowledges funding from the Science and Engineering Research Board (SERB), Govt. of India grant numbers SB/S2/RJN-080/2014 and ECR/2016/001044, and DRDO CARS no.: MPG/SO/2016-17-11500/128/Him-Parv (R). MSS acknowledges fellowship from Dept. of Science and Technology (DST), Govt. of India INSPIRE Fellowship no. IF160281. P.K., A.K.D. and M.S.S. acknowledge the Indian Institute of Science Education and Research (IISER) Bhopal High performance Computing (HPC) facility for performing all model simulations. MFA is supported by Inspire Faculty Award Grant from DST-INSPIRE.

\section{Author contributions}

A.B., P.K. designed the study. P.K. took overall lead in designing the model experiment. P.K. and A.K.D. performed the model simulations. P.K. and M.S.S. processed and analyzed model data, and created the figures. A.B. took overall lead in interpretation and analysis of the results. A.B., P.K. and M.F.A. wrote the paper with help from R.M. and M.S.S. R.M. contributed to sharpening the questions. Figure S2 is prepared by M.S.S. and P.K. All authors participated in discussions.

\section{Competing interests}

The authors declare no competing interests.

\section{Additional information}

Supplementary information is available for this paper at https://doi.org/10.1038/s41598-019-54553-9.

Correspondence and requests for materials should be addressed to P.K. or A.B.

Reprints and permissions information is available at www.nature.com/reprints.

Publisher's note Springer Nature remains neutral with regard to jurisdictional claims in published maps and institutional affiliations.

(c) (i) Open Access This article is licensed under a Creative Commons Attribution 4.0 International License, which permits use, sharing, adaptation, distribution and reproduction in any medium or format, as long as you give appropriate credit to the original author(s) and the source, provide a link to the Creative Commons license, and indicate if changes were made. The images or other third party material in this article are included in the article's Creative Commons license, unless indicated otherwise in a credit line to the material. If material is not included in the article's Creative Commons license and your intended use is not permitted by statutory regulation or exceeds the permitted use, you will need to obtain permission directly from the copyright holder. To view a copy of this license, visit http://creativecommons.org/licenses/by/4.0/.

(c) The Author(s) 2019 